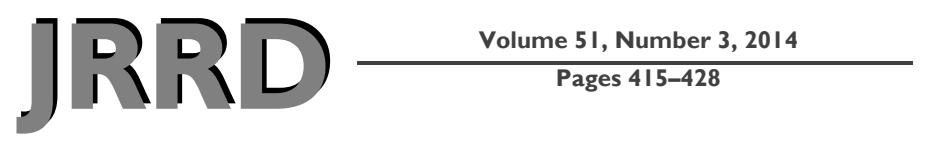

\title{
Prospective prediction of functional difficulties among recently separated Veterans
}

\author{
Gerald E. Larson, $\mathbf{P h D ;}{ }^{1}$ Sonya B. Norman, $\mathbf{P h D}^{\mathbf{2}^{*}}$ \\ ${ }^{1}$ Naval Health Research Center, San Diego, CA; ${ }^{2}$ National Center for PTSD, San Diego, CA; Department of Veterans \\ Affairs Center of Excellence in Stress and Mental Health, San Diego CA; and School of Medicine, University of California, \\ San Diego, San Diego, CA
}

\begin{abstract}
Reports of functional problems are common among Veterans who served post-9/11 (more than 25\% report functional difficulties in at least one domain). However, little prospective work has examined the risk and protective factors for functional difficulties among Veterans. In a sample of recently separated Marines, we used stepwise logistic and multiple regressions to identify predictors of functional impairment, including workrelated problems, financial problems, unlawful behavior, activity limitations due to mental health symptoms, and perceived difficulty reintegrating into civilian life. Posttraumatic stress disorder symptoms assessed both before and after military separation significantly predicted functional difficulties across all domains except unlawful behavior. Certain outcomes, such as unlawful behavior and activity limitations due to mental health symptoms, were predicted by other or additional predictors. Although several forms of functioning were examined, the list was not exhaustive. The results highlight a number of areas where targeted interventions may facilitate the reintegration of military servicemembers into civilian life.
\end{abstract}

Key words: financial problems, functional impairment, mental health, military, posttraumatic stress disorder, prospective, PTSD, reintegration, risk factors, Veterans, work functioning.

\section{INTRODUCTION}

Studies suggest that Iraq or Afghanistan Veterans (Operation Iraqi Freedom/Operation Enduring Freedom
[OIF/OEF] or Operation New Dawn) who have recently separated from the military face many challenges reintegrating into civilian life. A recent nationally representative survey indicated that 44 percent of post-9/11 Veterans report difficulties readjusting to civilian life [1]. Reintegration challenges manifest in a variety of ways, including functional problems in social, family, school, work, and community domains [2-8]. Such difficulties have implications for Veterans' quality of life.

Sayer et al. (2010) documented the prevalence and types of community reintegration problems among 754 post-9/11 combat Veterans receiving Department of Veterans Affairs (VA) medical care [6]. A large number, 25 to 56 percent, of combat Veterans reported "some" to "extreme" difficulty in one or more domains, including social functioning, productivity, community involvement, and self-care. Also, 57 percent of these Veterans reported

Abbreviations: CD-RISC = Connor-Davidson Resilience Scale, CI = confidence interval, DRRI = Deployment Risk and Resilience Inventory, OIF/OEF = Operation Iraqi Freedom/ Operation Enduring Freedom, OR = odds ratio, PTSD = posttraumatic stress disorder, TAP $=$ Transition Assistance Program, TICS = Two-Item Conjoint Screen, VA = Department of Veterans Affairs.

*Address all correspondence to Sonya B. Norman, PhD; VA San Diego Healthcare System, 3350 La Jolla Village Dr, San Diego, CA 92161. Email: snorman@ucsd.edu http://dx.doi.org/10.1682/JRRD.2013.06.0135 
heightened problems with anger control and 40 percent reported at least some civilian readjustment struggles in the past $30 \mathrm{~d}$. These high rates underscore the need to understand factors that place recently separated Veterans at risk for functional difficulties and more broadly at risk for difficulty reintegrating into civilian life.

To date, posttraumatic stress disorder (PTSD) is the risk factor for functional difficulties that has received the most attention [9-12]. In a population-based study of more than 18,000 soldiers, almost all soldiers who reported symptoms consistent with a PTSD diagnosis also reported functional impairment, often at a "very difficult" or "extremely difficult" level [8]. A review by Schnurr and colleagues (2009) compared research findings on post-9/11 Veterans with those from both earlier waves of Veterans and prior civilian samples [12]. Similar patterns emerged across cohorts: those with PTSD were far more likely to manifest limitations in functioning than those without PTSD. Among studies that examined PTSD symptom severity rather than presence or absence of diagnosis, greater symptom severity tended to be positively correlated with greater impairment. In the National Vietnam Veterans Readjustment Study, PTSD status was strongly associated with physical limitations, not working, compromised physical health, and diminished well-being, even when controlling for demographic factors and other comorbid conditions such as depression, alcohol use disorder, panic disorder, and other medical conditions [13].

Fewer studies have looked beyond PTSD when examining risk for functional impairment among post-9/11 Veterans. In one such study, alcohol dependence and drug use were associated with impairments in work output and physical performance, and anger and alienation predicted engagement in more dangerous behaviors [9]. A separate study found that greater pain was associated with impaired physical role functioning among OIF/OEF Veterans presenting to a deployment health clinic, even when controlling for age, sex, and mental health conditions [14]. Among Veterans participating in VA medical care, selfreported difficulty controlling violent behavior was associated with having been deployed for more than a year and having fired a weapon in a combat situation, as well as having current PTSD hyperarousal symptoms [15]. This study is promising in that it invites further investigation of deployment factors that may impair functioning among Veterans. However, the study was limited in that all selfreports were retrospective and thus could have been biased by current distress and impairment.
In their 2009 review of the literature on functional impairment among post-9/11 Veterans, Schnurr and colleagues stressed the need for more thorough studies that examine multiple predictors and multiple functional outcomes using a longitudinal framework [12]. To improve knowledge of risk for functional impairment in post-9/11 Veterans, researchers need to examine a broad range of variables occurring both during military service and following separation. Also of importance is the need to enroll nonclinical samples for optimal generalizability across broad swaths of Veterans.

The goal of the current study was to identify risk and protective factors for functional impairment in post-9/11 Veterans during initial reentry into civilian life. Predictors were drawn from multiple time periods, including deployments, the months leading up to separation from the military, and the initial months of readjustment to civilian life following separation from the military. Outcomes included several domains of functioning, including financial wellbeing, work-related problems, unlawful behaviors, and general limitations due to mental health problems. Overall perception of adjustment to civilian life was also examined. We hypothesized that, consistent with other studies, PTSD symptoms would predict risk for functional difficulties during the civilian reintegration period. However, we also hypothesized that multivariate models (including PTSD) would provide significantly greater explanatory power than PTSD alone.

\section{METHODS}

\section{Procedures}

The study was approved by the Naval Health Research Center Institutional Review Board and consisted of two periods: preseparation (time 1) and postseparation (time 2). During time 1, U.S. Marine Corps personnel enrolled in a mandatory preseparation Transition Assistance Program (TAP) course were invited to participate in a voluntary survey. TAP includes a week of classes on topics such as career skills development, job search techniques, and information on Veterans' benefits. Data were collected between January and April 2010 at six Marine Corps installations hosting TAP classes. Across sites, 2,943 Marines, representing 55 percent of eligible Marines in the TAP classes, completed consent procedures and the survey during lunch breaks. 
Time 2 began approximately 9 mo after the TAP classes, when a follow-up survey was sent by both mail and email to the 2,116 baseline participants who consented during the initial survey to be recontacted; a small monetary incentive was also offered. Participants were given the option of mailing back the paper questionnaire or completing the questionnaire via the Internet. All eligible participants had transitioned from Active Duty military and had been reintegrating into civilian life for a minimum of $2 \mathrm{mo}$. The follow-up response rate was 25 percent. Note that this may be an underestimation because a large number of participants who completed the baseline survey were ineligible for the follow-up or were not locatable. However, because these data were not collected for the full sample, we report the more conservative response rate. The sample for whom follow-up data were available, compared with the sample for whom only baseline data were available, was slightly older (mean age 26.6 and 24.3, respectively, $t=8.61, p<$ 0.001 ), had a slightly greater number of combat deployments (mean 2.6 and 2.4, respectively, $t=3.97, p<0.001$ ), and had a greater proportion of officers ( $7 \%$ vs $2 \%$, respectively, chi-square $=30.2, p<0.001$ ).

\section{Measures}

The Figure shows the measures administered at time 1 and time 2.

\section{Outcome Measures}

Functional domains of unlawful behavior, financial problems, and work-related problems were examined. In addition, global readjustment was evaluated by assessing limitations due to mental health and difficulties reintegrating into civilian life.

Unlawful behavior. Participants were coded as engaging in unlawful behavior if they positively endorsed at least one of the following, all of which were anchored to the postseparation time frame: having been arrested; having warrants, restraining orders, or disciplinary actions pending against them; being on probation or parole; or driving a car or other vehicle after having too much to drink.

Financial problems. Participants were asked in a yes/ no format if they had trouble paying their bills; were currently experiencing trouble paying their mortgage or going through a foreclosure; or had any significant outstanding past-due debts, alimony, or child support. Those who positively endorsed at least one of these items were coded as having financial problems.

Work-related problems. If participants indicated that a physical or emotional problem had caused them to be late for work more than three times or lose a job since

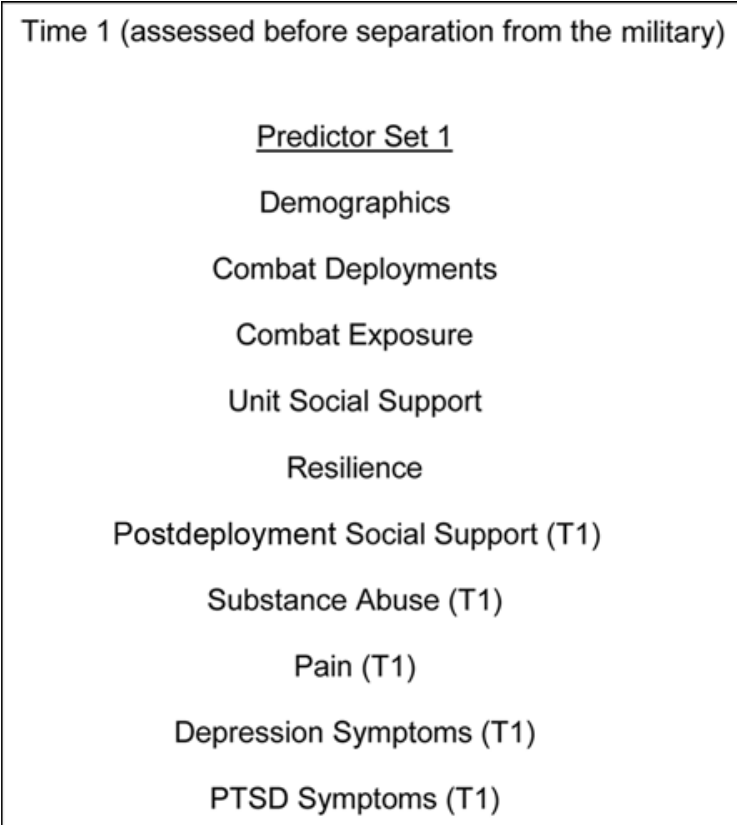

Figure.

Assessment timeline. PTSD = posttraumatic stress disorder, $\mathrm{T} 1=$ time $1, \mathrm{~T} 2=$ time 2 . 
leaving Active Duty, they were coded as having had work-related problems.

Limitations due to mental health. Participants responded to an item asking "During the past 30 days, how often did poor mental health keep you from doing your usual activities, such as work or recreation?" Responses were captured on a 1-7 scale ( 1 = "never" and 7 = "28-30 d"). This item was adapted from the Health Related Behaviors Survey [2].

Readjustment to civilian life. Participants responded to an item asking "How much trouble have you had adjusting to civilian life?” A 1-4 response scale was used (1 = "none at all" and 4 = “a lot”).

\section{Predictor Variables: Demographics}

The surveys assessed sex, age, military pay grade, marital status, race/ethnicity, and time since separation.

\section{Measures Unique to Preseparation Surveys}

Combat-related events. Number of career combat deployments was assessed, with response options of 0,1 , 2 , or 3 or more. Combat exposure during the most recent deployment was measured with 18 items describing potentially traumatic combat experiences (e.g., "I was responsible for the death or serious injury of an enemy.”). These items were adapted from previously published measures of combat [16-18]. Respondents rated the frequency with which they had experienced each event on a scale ranging from 1 ("never") to 5 (“51+ times"). Responses were summed to compute a total combat exposure score. The measure had very strong internal consistency for this sample $(\alpha=0.90)$. The Unit Support Scale from the Deployment Risk and Resilience Inventory (DRRI) [19] was administered to assess social support during deployment. The Unit Support Scale is a 12item instrument assessing support from military peers and satisfaction with leadership. Items include "My unit was like a family to me," "I could go to most people in my unit for help when I had a personal problem," and "My superiors made a real attempt to treat me as a person.” Responses were summed. The scale had high internal consistency in the present sample $(\alpha=0.95)$.

Resilience. The 25-item Connor-Davidson Resilience Scale (CD-RISC) was used to measure resilience [20] over the past month. Each item was rated from 0 ("not at all true") to 4 ("true nearly all of the time"). Higher scores corresponded to greater resilience. The CD-RISC has been tested in both community and clinical samples and has demonstrated good internal consistency (Cronbach $\alpha=0.89)$ and test-retest reliability ( $r=0.87)$ [21]. Cronbach $\alpha$ for the present sample was 0.94.

\section{Measures Unique to Reintegration Surveys}

Spiritual beliefs were measured with two items asking how strongly participants agreed with the statements "My religious/spiritual beliefs are a very important part of my life" and "My religious/spiritual beliefs influence how I make life decisions" [2]. Responses ranged from 1 ("strongly disagree") to 4 ("strongly agree"), and scores for the two items were summed. Posttraumatic Growth was measured using the Posttraumatic Growth Inventory [22], a 21-item scale that includes factors measuring New Possibilities, Relating to Others, Personal Strength, Spiritual Change, and Appreciation of Life following trauma. Items were rated on a scale from 1 ("I did not experience this change") to 6 ("I experienced this change to a very great degree”). Internal consistency was high for the present sample $(\alpha=0.92)$.

\section{Measures Administered on Preseparation Surveys and Readministered on Reintegration Surveys}

Social support was measured with the Postdeployment Social Support Scale from the DRRI. This scale uses 15 items to assess the extent to which family, friends, coworkers, employers, and community provided emotional sustenance and instrumental assistance. Items include "Among my friends or relatives, there is someone who makes me feel better when I am feeling down," and "There are people to whom I can talk about my deployment experiences.” A 5-point Likert scale ( 1 = "strongly disagree" and 5 = "strongly agree") was used. At preseparation, the full scale was used and items were anchored to support received upon return from deployment. At reintegration, 3 deployment-specific items were dropped and the remaining 12 items were anchored to current social relationships. The scale had good internal consistency in the present sample $(\alpha=0.88)$. The Two-Item Conjoint Screen (TICS) [23] was used to screen for problematic alcohol use. The TICS asks whether participants have drunk alcohol more than they meant to and have they felt a need to cut down on drinking. References to drug use were omitted from the baseline TICS because of a Navy Institutional Review Board directive. At reintegration, the items included "or used drugs" in addition to asking about alcohol use. On the follow-up survey, participants 
answered yes or no to the following items: "Since leaving the military, have you ever drunk alcohol or used drugs more than you meant to?" and "Have you felt you wanted or needed to cut down on your drinking or drug abuse since leaving the military?”

Participants were coded as positive for alcohol/substance misuse if they endorsed either item. Prior studies have shown an 80 percent sensitivity to substance use problems using this coding method [23]. On the preseparation survey, pain was measured with a single item asking "How much bodily pain have you had during the past 4 weeks?” This item was adapted from Hayes et al. [24]. A 6-point Likert scale ( 1 = "none" and 6 = "very severe") was used. At reintegration, pain was measured with two items. The first addressed frequency: "During the past 4 weeks, how often did you have pain or discomfort?” A Likert scale ranging from 1 ("once or twice") to 5 ("almost every day") was used. The second pain item was a 20-point visual analog scale: "Please select the one number that best describes your pain on the average over the past 4 weeks" ( $0=$ "no pain" and $20=$ "pain as bad as you can imagine"). The two reintegration pain items were multiplied for a total pain score.

Depression symptoms were assessed with the 20item Center for Epidemiologic Studies Depression Scale [25]. Responses were scored from 0 ("rarely or none of the time") to 3 ("most or all of the time") and items were summed for a total score. The scale had good internal consistency in the present sample $(\alpha=0.91)$. PTSD symptom severity was measured with the PTSD Checklist-Civilian Version [26], a 17-item self-report measure asking participants how bothered they have been by PTSD symptoms over the past month. Responses ranged from 0 ("not at all") to 4 ("extremely") and were summed for a total score. The scale had strong internal consistency in the present sample $(\alpha=0.96)$.

\section{Analysis Plan}

Continuous variables were examined to ensure that the assumption of normality was met. Unadjusted odds ratios (ORs) were computed for predictors of dichotomously scored functional outcomes (unlawful behavior, financial functioning, and work-related functioning). Bivariate correlations were computed between the predictor variables and scaled outcomes (limitations due to mental health problems, difficulty reintegrating into civilian life). Predictors were correlated with each other to determine multicollinearity. PTSD and depression symptom scores were multicollinear with correlations of 0.81 preseparation and 0.80 at reintegration. Based on the study goal of evaluating hypotheses regarding PTSD and functioning, we decided to include PTSD symptom scores in the models and exclude depression symptom scores from the analyses. All predictors having significant bivariate associations with outcomes were included in multivariate analyses for those outcomes. Regression models were run such that block 1 included all variables of interest up to the time of separation from the military (demographics, deployment-related variables, and other preseparation variables). Block 2 added variables from the time of civilian reintegration (following military separation). To further examine the influence of PTSD, we recoded PTSD at reintegration to four categories based on standard deviations above and below the mean. This recoded variable was used to compute unadjusted ORs reflecting outcome differences as a function of a standard deviation increase in PTSD scores. Multivariate analyses were also run excluding deployment variables that were significant in univariate analyses because not all Veterans deployed. This did not change which variables were significant in any of the multivariate models; thus, these analyses are not reported.

\section{RESULTS}

A large majority of participants were male (92\%); enlisted (93\%); and separating because of retirement, expiration of enlistment term, or parenthood (93.2\%) (Table 1). Seventy-three percent of the participants were Caucasian. Mean, standard deviation, and range values for predictor and continuous outcome variables are shown in Table 1. All continuous variables met the assumption of normality.

\section{Domain-Specific Functional Outcomes}

Table 2 shows unadjusted ORs for predictors of dichotomous outcomes representing unlawful behavior, financial problems, and work-related problems. Also shown are correlations between predictor variables and the continuous outcomes of limitations due to mental health concerns and difficulty readjusting to civilian life, respectively. Prevalence rates for each functional outcome, adjusted $R^{2}$ for PTSD symptoms at preseparation and at reintegration and adjusted ORs (both for the first block and the final model) are reported in Table 3 . The prevalence of functional impairment ranged from 4.4 percent for self- 
JRRD, Volume 51, Number 3, 2014

Table 1.

Participant characteristics.

\begin{tabular}{|c|c|c|c|}
\hline Characteristic & $n(\%) *$ & Mean \pm SD & Range \\
\hline Age, yr & 461 & $27.4 \pm 7.1$ & $19-55$ \\
\hline \multicolumn{4}{|l|}{ Sex } \\
\hline Female & $38(8.0)$ & - & - \\
\hline \multicolumn{4}{|l|}{ Pay Grade } \\
\hline \multicolumn{4}{|l|}{ Ethnicity } \\
\hline Caucasian (non-Hispanic) & $346(73.0)$ & - & - \\
\hline African American & $37(7.8)$ & - & - \\
\hline Hispanic/Latino & $71(15.0)$ & - & - \\
\hline \multicolumn{4}{|l|}{ Marital Status } \\
\hline Married & 193 (40.7) & - & - \\
\hline Single & $281(59.3)$ & - & - \\
\hline \multicolumn{4}{|l|}{ Reason for Separation } \\
\hline $\begin{array}{l}\text { Disability, dependency, hardship, or physical or mental } \\
\text { condition that interferes with service }\end{array}$ & $23(4.9)$ & - & - \\
\hline Retirement, expiration of term, or parenthood & $442(93.2)$ & - & - \\
\hline Missing & $9(1.9)$ & - & - \\
\hline \multicolumn{4}{|l|}{ Deployment } \\
\hline Social support & 393 & $34.9 \pm 9.7$ & $15-71$ \\
\hline Pain & 470 & $3.3 \pm 1.2$ & $1-6$ \\
\hline Depression & 467 & $16.3 \pm 11.4$ & $0-56$ \\
\hline PTSD & 458 & $37.7 \pm 17.0$ & 17-85 \\
\hline \multicolumn{4}{|l|}{ Reintegration } \\
\hline Positive alcohol/drug screen & $141(29.7)$ & - & - \\
\hline Spirituality & 459 & $5.1 \pm 2.1$ & $2-8$ \\
\hline Posttraumatic growth & 458 & $33.6 \pm 13.7$ & $10-60$ \\
\hline Social support & 440 & $26.9 \pm 7.9$ & $12-56$ \\
\hline Pain & 471 & $23.9 \pm 23.6$ & $0-100$ \\
\hline Depression & 462 & $15.3 \pm 11.9$ & $0-60$ \\
\hline PTSD & 452 & $34.4 \pm 17.4$ & $17-85$ \\
\hline
\end{tabular}

${ }^{*} n$ values vary because of missing data, particularly for nondeployers who were ineligible to complete deployment-anchored items. PTSD = posttraumatic stress disorder, $\mathrm{SD}=$ standard deviation . 
Table 2.

Unadjusted odds ratios (ORs) or bivariate correlations for predictors of functional outcomes.

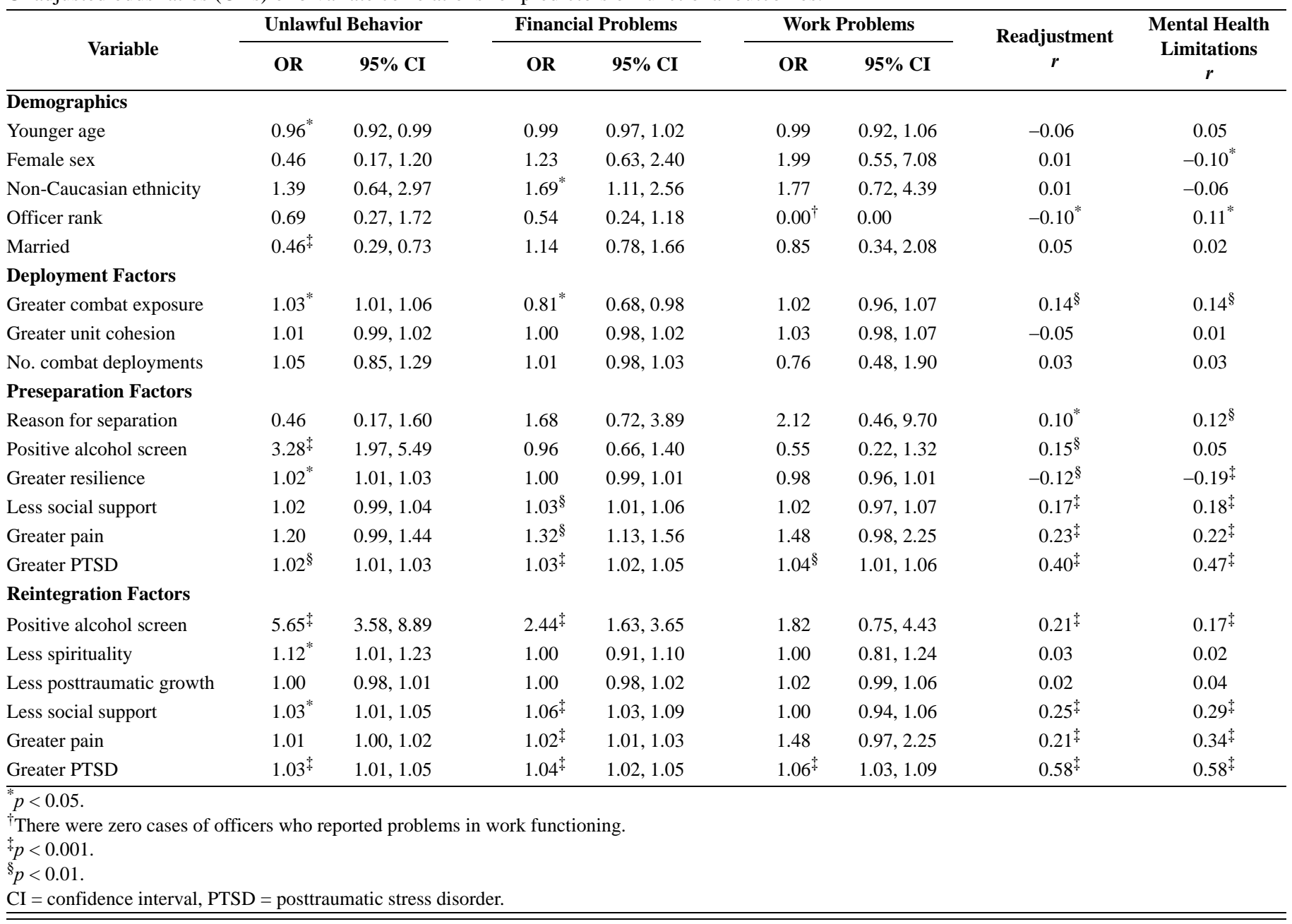

reported work problems to 40.1 percent for self-reported financial problems.

\section{Unlawful Behavior}

PTSD symptoms were not significant in the multivariate analyses for unlawful behavior. A positive alcohol screen preseparation more than doubled the odds of taking part in unlawful behavior during reintegration $(\mathrm{OR}=2.29$; $95 \%$ confidence interval [CI]: 1.24, 4.19). Greater combat exposure was also significantly associated with unlawful behavior (OR = 1.04; 95\% CI: 1.01, 1.07). Being married $(\mathrm{OR}=0.39 ; 95 \% \mathrm{CI}: 0.21,0.70)$ and greater resilience $(\mathrm{OR}=0.98 ; 95 \% \mathrm{CI}: 0.96,0.99)$ were protective against unlawful behavior. In the final model, a positive alcohol screen during reintegration increased odds of unlawful behavior fourfold (OR $=4.65$; 95\% CI: 2.48, 8.71), while greater resilience $(\mathrm{OR}=0.97 ; 95 \% \mathrm{CI}: 0.95,0.99)$ and being married $(\mathrm{OR}=0.40$; 95\% CI: $0.20,0.80)$ were protective.

\section{Financial Problems}

After the first block, in addition to preseparation PTSD symptoms, non-Caucasian ethnicity $(\mathrm{OR}=1.98 ; 95 \% \mathrm{CI}$ : $1.17,3.33$ ) was a significant risk factor for financial problems. In the final model, in addition to PTSD during reintegration, being non-Caucasian (OR $=1.80$; 95\% CI: 1.04, 3.10) significantly increased risk of financial problems. Finally, for every 1 standard deviation increase in PTSD symptom score, the odds of having financial problems increased 1.5-fold (OR = 1.45; 95\% CI: 1.04, 2.03). 
JRRD, Volume 51, Number 3, 2014

Table 3.

Logistic regression models for posttraumatic stress disorder predicting functional impairment.

\begin{tabular}{|c|c|c|c|c|c|c|c|}
\hline \multirow{2}{*}{ Outcome } & \multirow{2}{*}{$\begin{array}{c}\text { Positive, } \\
n(\%)\end{array}$} & \multicolumn{3}{|c|}{ Block 1 Model } & \multicolumn{3}{|c|}{ Final Model } \\
\hline & & Adjusted $R^{2}$ & Adjusted OR & $95 \% \mathrm{CI}$ & Adjusted $R^{2}$ & Adjusted OR & $95 \% \mathrm{CI}$ \\
\hline Unlawful Behavior & $113(23.8)$ & 0.15 & 1.01 & $0.99,1.03$ & 0.27 & 1.02 & $0.99,1.05$ \\
\hline Work Problems & $21(4.4)$ & 0.11 & $1.03^{*}$ & $1.01,1.06$ & 0.23 & $1.07^{*}$ & $1.03,1.10$ \\
\hline $\begin{array}{l}{ }^{*} p<0.001 \\
{ }^{\dagger} p<0.05 . \\
\mathrm{CI}=\text { confidence interv }\end{array}$ & = odds ratio. & & & & & & \\
\hline
\end{tabular}

\section{Work-Related Problems}

In addition to significant variables listed in Table 2, time in months since becoming a civilian was included as a covariate in block 1 to control for the possibility that individuals who had very recently separated would be less likely to be employed. In block 1, both preseparation PTSD symptoms and time since becoming a civilian $(\mathrm{OR}=1.30$; $95 \%$ CI: $1.04,1.63)$ contributed to the model. In the final model, in addition to PTSD during reintegration, time since becoming a civilian significantly contributed to the model $(\mathrm{OR}=1.32$; 95\% CI: 1.05, 1.66). For every 1 standard deviation increase in PTSD symptom score, the odds of having work-related problems increase more than threefold ( $\mathrm{OR}=$ 3.30; 95\% CI: 1.65, 6.60).

\section{Global Reintegration Outcomes}

Table 2 shows correlations between predictor variables and the global outcomes of civilian readjustment problems and mental health-related limitations, respectively. Table 4 shows adjusted $R^{2}$ for the final models predicting civilian readjustment problems and mental health-related limitations, respectively. As shown, the models explained approximately one-third of the variance in each outcome.

\section{Reintegration to Civilian Life}

In block 1, only higher preseparation PTSD scores predicted greater difficulties reintegrating to civilian life. In the final model, only PTSD during reintegration significantly predicted greater reintegration difficulties $(r=$ $0.58, p<0.05)$.

\section{Limitations Due to Mental Health Problems}

In block 1, higher preseparation PTSD scores predicted greater limitations due to mental health. In block 2 (the reintegration period), PTSD symptoms during reintegration predicted greater limitations due to mental health. Preseparation PTSD symptoms (standardized $\beta$ in block 2 for preseparation PTSD $=0.15 ; p<0.05$ ), pain during reintegration $(\beta=0.11 ; p<0.05)$ and social support during reintegration $(\beta=0.12 ; p<0.05)$ also significantly contributed to the model.

\section{DISCUSSION}

We examined a series of demographic, preseparation, and postseparation variables as predictors of functional

Table 4.

Multiple regression models for posttraumatic stress disorder (PTSD) predicting reintegration difficulties and limitations due to mental health.

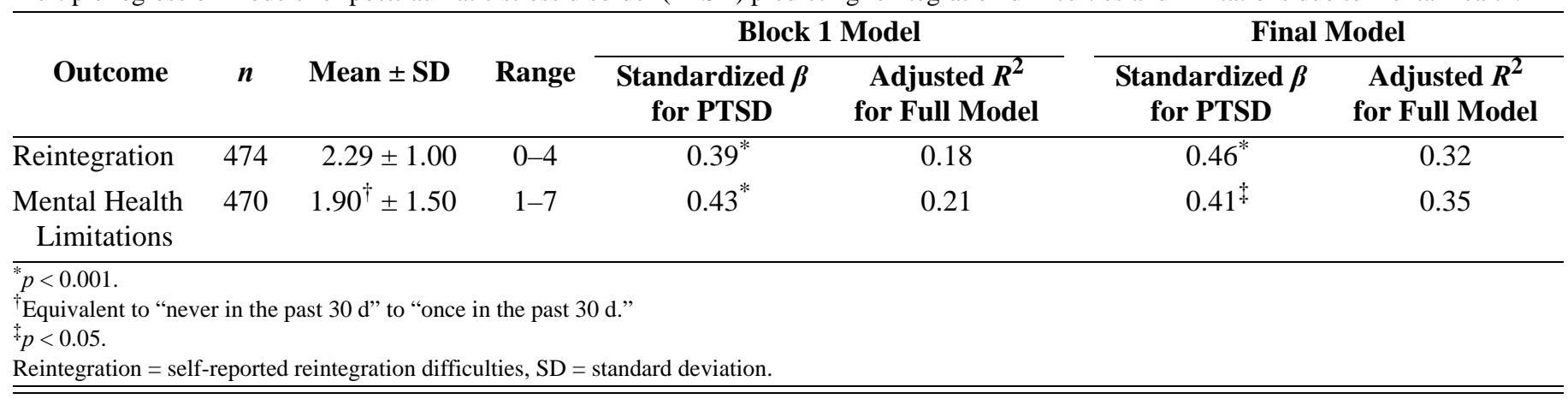


problems during the initial year of Veterans' reintegration into civilian life following completion of military service. Domains of functioning examined included unlawful behavior, financial problems, and work-related problems. In addition, we examined predictors of self-reported difficulty with reintegration, and limitations due to mental health. As hypothesized, PTSD symptoms predicted difficulty across almost all domains of functioning (other than unlawful behavior), even when controlling for other factors. The fact that PTSD symptoms were the most consistent predictor of functional status reinforces the importance of early and effective recovery-oriented PTSD treatment.

We used stepwise multiple regressions to examine predictors of functional problems at two time points during which remedial efforts could be implemented: the time leading up to separation from military service followed by the initial reintegration into civilian life. Knowledge before separation regarding risk and protective factors for later functional impairment can be used to inform programmatic changes, such as more rigorous attempts to identify and support individuals at high risk for reintegration difficulty. Since preseparation PTSD symptom severity predicted multiple types of functional problems during reintegration, offering resources such as PTSD treatment at the time of separation may help to reduce the risk of functional difficulties several months later. PTSD is a treatable disorder. Alleviation of symptoms may greatly reduce risk of functional difficulties during reintegration to civilian life. Future research is necessary to evaluate whether PTSD treatment close to the time of discharge can reduce the risk of functional difficulties during the first year following separation.

Information about other risk factors such as positive alcohol/substance use screens or marital status can further guide prevention efforts targeted at specific populations. Targeted prevention efforts based on characteristics of a specific population are generally more effective than universal or more generic prevention messages [27]. The findings also highlight the need for comprehensive evaluations of known risk factors.

When examining the final models, concurrent PTSD symptoms of 1 standard deviation above the mean increased the risk of functional difficulties other than unlawful behavior anywhere from 1.5 to 3.5 times. This is consistent with a much earlier study identifying PTSD as the strongest predictor of concurrent functional problems exhibited by Vietnam Veterans more than $20 \mathrm{yr}$ after the end of that war [13] and with a newer review indicating that PTSD consistently emerges as a correlate of functioning difficulties in post-9/11 Veterans [12].

Not surprisingly, Veterans with a positive alcohol screen (preseparation or reintegration) were at increased risk of engaging in unlawful behavior during reintegration. In fact, the risk of engaging in unlawful behavior was twofold for those with a positive screen preseparation and fourfold postseparation. Greater combat exposure also increased risk, and greater resilience and being married were protective against engaging in unlawful behavior. Notably, only for unlawful behavior were PTSD symptoms not predictive of reintegration difficulty, possibly because drinking behavior accounted for such substantial variance in this model. This finding highlights the need for continued efforts to mitigate drinking, especially among young male servicemembers and Veterans. It also highlights the need to evaluate multiple factors, such as demographics and alcohol and substance use, when considering someone's risk for engaging in unlawful behavior.

\section{CONCLUSIONS}

This study extends previous work in several ways. Zatzick et al. (1997) primarily examined functional domains related to physical limitations and well-being [13]. This study builds upon their work by showing that PTSD symptoms had a similar relationship to additional domains of functioning, including financial problems. Zatzick et al.'s study used data collected nearly $20 \mathrm{yr}$ after combat exposure. Our data show similar relationships between PTSD symptoms and functioning in a much younger and more recently separated cohort of Veterans. This is among the first studies to simultaneously examine risk factors from multiple time points using longitudinal data. The findings suggest that early screening and treatment of PTSD and problem drinking is important not only for symptom reduction, but also for helping Veterans reintegrate successfully into civilian society. If Veterans are unable to, for example, maintain employment or successfully manage finances, these early functional difficulties may form a vicious cycle. For all young adults, achieving financial independence and successful employment is critical to reaching autonomous participation in adult life. The inability to achieve such independence is considered a risk for functional problems throughout the life span (e.g., [28-29]). 
While PTSD symptoms predicted all functional outcomes that we examined other than unlawful behavior, other risk and protective factors were unique to specific domains. For example, non-Caucasian ethnicity was a risk factor for financial problems. Additional research is needed to understand associations between ethnicity and financial difficulties following separation.

Individuals reporting activity limitations due to mental health problems during reintegration concurrently reported greater pain and less social support. The finding regarding pain is of particular concern since studies of OIF/OEF Veterans have found prevalence rates for chronic widespread pain ranging from 29 to 47 percent $[14,30]$. Pain is often comorbid with mental health conditions such as PTSD and depression (e.g., [31,32]); thus, it is not surprising that individuals who are limited by their mental health conditions may also report high levels of pain. Like pain, social support also has a strong relationship with mental health problems, with low social support generally being a risk factor for more severe presentations of psychopathology and poorer treatment response (e.g., [33]).

For work-related problems (controlling for time since separation), only PTSD symptoms predicted functional impairment. Similarly, only PTSD symptoms at both time points of interest predicted greater difficulty with reintegration to civilian life. It is possible that the emotional distress and symptoms associated with PTSD are most salient to Veterans in assessing their overall reintegration experience.

It is noteworthy that greater combat exposure was predictive of all but work problems when examining the unadjusted ORs, although this variable was no longer significant following inclusion of factors more temporally proximal to the outcomes. Across a number of studies, combat exposure has been linked with PTSD in a "dose response” manner, with greater severity of combat exposure associated with greater likelihood and greater severity of PTSD symptoms [34-37]. In a retrospective study, Iversen and colleagues (2008) found that combat-related experiences were the strongest predictor of PTSD in a sample of U.K. military personnel when evaluating demographic, predeployment, and deployment-related factors [34]. However, the relationship between combat exposure and functioning in the civilian world has received little attention. Results of our study suggest that while factors following separation from the military have a primary role in predicting functional difficulties during reintegration into civilian life, high combat exposure may nevertheless be an early indicator of future risk.

A limitation of this study was that PTSD and depression symptoms were multicollinear. This is consistent with the hypothesis that these disorders may be different permeations of one underlying response to trauma (e.g., [38]). Because the correlation between PTSD and depression was so high, it was not possible to decipher whether PTSD had a unique role in functional difficulties or whether mental health problems or emotional distress more broadly, rather than PTSD specifically, play this function. Examination of alternative data where PTSD and depression symptoms do not correlate as highly would be informative, as would studies using diagnostic interviews rather than self-report.

Several additional limitations to this study should be considered. The follow-up response rate of 25 percent was low, raising the question of whether the study cohort was representative of the larger sample of separating Marines. However, as noted, this is a conservative estimate of the response rate. Although we were able to examine several forms of functioning, the list was not comprehensive. Notably, data regarding family and relationship functioning were unavailable. Similarly, although we examined a large set of predictor variables, not all previously identified risk and protective factors were included in the data set. Because the sample consisted exclusively of Veterans who had served in the Marines, it is not clear the extent to which the findings generalize to Veterans of other military branches.

Another limitation is that, as in much previous research [6], global perceptions of reintegration were measured with a single item. Similarly, each functioning domain was not measured exhaustively, and therefore the prevalence estimates for various forms of impairment may shift with different metrics. For example, other aspects of work-related problems may include employment duration or positive performance reviews. Scales that measure multiple aspects of each domain may be needed to further advance understanding of functioning and civilian readjustment.

This study provides the most comprehensive examination to date of the relationship between PTSD and functioning in a nonclinical sample of post-9/11 Veterans. It is also among the first studies to use longitudinal data to examine a broad range of risk factors for functional impairment. The findings provide support for the relationship between PTSD symptoms and functional difficulties 
in Veterans reintegrating into civilian life, highlighting the importance of identifying, preventing, and treating PTSD. They also highlight the need for comprehensive evaluations of multiple risk and protective factors to best understand risk for functional difficulties.

\section{ACKNOWLEDGMENTS}

\author{
Author Contributions: \\ Conceived project: G. E. Larson. \\ Procured funding: G. E. Larson. \\ Analyzed data: S. B. Norman. \\ Drafted and edited manuscript: G. E. Larson, S. B. Norman.
}

Financial Disclosures: The authors have declared that no competing interests exist.

Funding/Support: This material was based on work supported by the Navy Bureau of Medicine and Surgery, Washington, DC, under work unit 60812.

Institutional Review: Both the initial survey administered preseparation and the follow-up survey administered at reintegration were approved by the Naval Health Research Center Institutional Review Board.

Participant Follow-Up: The authors do not plan to inform participants of the publication of this study.

\section{REFERENCES}

1. Morin R. The difficult transition from military to civilian life. Pew research: social and demographic trends [Internet]. Washington (DC): Pew Research Center; 2011 Dec 8 [cited 2013 Aug 25]. Available from http://www. pewsocialtrends.org/2011/12/08/the-difficult-transitionfrom-military-to-civilian-life/

2. Bray RM. Department of Defense survey of health-related behaviors among Active Duty military personnel. Fort Belvoir (VA): Defense Technical Information Center; 2006.

3. Harvey SB, Hatch SL, Jones M, Hull L, Jones N, Greenberg N, Dandeker C, Fear NT, Wessely S. Coming home: Social functioning and the mental health of UK Reservists on return from deployment to Iraq or Afghanistan. Ann Epidemiol. 2011;21(9):666-72. [PMID:21737306] http://dx.doi.org/10.1016/j.annepidem.2011.05.004

4. Mansfield AJ, Bender RH, Hourani LL, Larson GE. Suicidal or self-harming ideation in military personnel transitioning to civilian life. Suicide Life Threat Behav. 2011; 41(4):392-405. [PMID:21599725] http://dx.doi.org/10.1111/j.1943-278X.2011.00039.x

5. Milliken CS, Auchterlonie JL, Hoge CW. Longitudinal assessment of mental health problems among active and reserve component soldiers returning from the Iraq war.
JAMA. 2007;298(18):2141-48. [PMID:18000197]

http://dx.doi.org/10.1001/jama.298.18.2141

6. Sayer NA, Noorbaloochi S, Frazier P, Carlson K, Gravely A, Murdoch M. Reintegration problems and treatment interests among Iraq and Afghanistan combat veterans receiving VA medical care. Psychiatr Serv. 2010;61(6): 589-97. [PMID:20513682] http://dx.doi.org/10.1176/appi.ps.61.6.589

7. Seal KH, Metzler TJ, Gima KS, Bertenthal D, Maguen S, Marmar CR. Trends and risk factors for mental health diagnoses among Iraq and Afghanistan veterans using Department of Veterans Affairs health care, 2002-2008. Am J Public Health. 2009;99(9):1651-58. [PMID:19608954] http://dx.doi.org/10.2105/AJPH.2008.150284

8. Thomas JL, Wilk JE, Riviere LA, McGurk D, Castro CA, Hoge CW. Prevalence of mental health problems and functional impairment among active component and National Guard soldiers 3 and 12 months following combat in Iraq. Arch Gen Psychiatry. 2010;67(6):614-23.

[PMID:20530011] http://dx.doi.org/10.1001/archgenpsychiatry.2010.54

9. Adler DA, Possemato K, Mavandadi S, Lerner D, Chang H, Klaus J, Tew JD, Barrett D, Ingram E, Oslin DW. Psychiatric status and work performance of veterans of Operations Enduring Freedom and Iraqi Freedom. Psychiatr Serv. 2011;62(1):39-46. [PMID:21209298] http://dx.doi.org/10.1176/appi.ps.62.1.39

10. Gellis LA, Mavandadi S, Oslin DW. Functional quality of life in full versus partial posttraumatic stress disorder among veterans returning from Iraq and Afghanistan. Prim Care Companion J Clin Psychiatry. 2010;12(3). [PMID:20944775]

11. Khaylis A, Polusny MA, Erbes CR, Gewirtz A, Rath M. Posttraumatic stress, family adjustment, and treatment preferences among National Guard soldiers deployed to OEF/OIF. Mil Med. 2011;176(2):126-31. [PMID:21366071] http://dx.doi.org/10.7205/MILMED-D-10-00094

12. Schnurr PP, Lunney CA, Bovin MJ, Marx BP. Posttraumatic stress disorder and quality of life: Extension of findings to veterans of the wars in Iraq and Afghanistan. Clin Psychol Rev. 2009;29(8):727-35. [PMID:19744758] http://dx.doi.org/10.1016/j.cpr.2009.08.006

13. Zatzick DF, Marmar CR, Weiss DS, Browner WS, Metzler TJ, Golding JM, Stewart A, Schlenger WE, Wells KB. Posttraumatic stress disorder and functioning and quality of life outcomes in a nationally representative sample of male Vietnam veterans. Am J Psychiatry. 1997;154(12):1690-95. [PMID:9396947]

14. Helmer DA, Chandler HK, Quigley KS, Blatt M, Teichman R, Lange G. Chronic widespread pain, mental health, and physical role function in OEF/OIF veterans. Pain Med. 
2009;10(7):1174-82. [PMID:19818029]

http://dx.doi.org/10.1111/j.1526-4637.2009.00723.x

15. Elbogen EB, Wagner HR, Fuller SR, Calhoun PS, Kinneer PM, Beckham JC; Mid-Atlantic Mental Illness Research, Education, and Clinical Center Workgroup. Correlates of anger and hostility in Iraq and Afghanistan war veterans. Am J Psychiatry. 2010;167(9):1051-58. [PMID:20551162] http://dx.doi.org/10.1176/appi.ajp.2010.09050739

16. Hoge CW, Castro CA, Messer SC, McGurk D, Cotting DI, Koffman RL. Combat duty in Iraq and Afghanistan, mental health problems, and barriers to care. N Engl J Med. 2004;351(1):13-22. [PMID:15229303] http://dx.doi.org/10.1056/NEJMoa040603

17. Keane TM, Fairbank JA, Caddell JM, Zimering RT, Taylor KL, Mora CA. Clinical evaluation of a measure to assess combat exposure. Psychological Assessment. J Consult Clin Psychol. 1989;1(1):53-55. [PMID:2647803]

18. Maguen S, Litz BT, Wang JL, Cook M. The stressors and demands of peacekeeping in Kosovo: Predictors of mental health response. Mil Med. 2004;169(3):198-206. [PMID:15080239]

19. King D, King L, Vogt D. Manual for the Deployment Risk and Resilience Inventory (DRRI): A collection of measures for studying deployment-related experiences of military veterans. Boston (MA): National Center for PTSD; 2003.

20. Connor KM, Davidson JR. Development of a new resilience scale: The Connor-Davidson Resilience Scale (CDRISC). Depress Anxiety. 2003;18(2):76-82.

[PMID:12964174]

http://dx.doi.org/10.1002/da.10113

21. Connor KM, Davidson JR, Weisler RH, Zhang W, Abraham K. Tiagabine for posttraumatic stress disorder: Effects of open-label and double-blind discontinuation treatment. Psychopharmacology (Berl). 2006;184(1):21-25. [PMID:16341846] http://dx.doi.org/10.1007/s00213-005-0265-3

22. Tedeschi RG, Calhoun LG. The Posttraumatic Growth Inventory: Measuring the positive legacy of trauma. J Trauma Stress. 1996;9(3):455-71. [PMID:8827649] http://dx.doi.org/10.1002/jts.2490090305

23. Brown RL, Leonard T, Saunders LA, Papasouliotis O. A two-item conjoint screen for alcohol and other drug problems. J Am Board Fam Pract. 2001;14(2):95-106. [PMID:11314930]

24. Hayes V, Morris J, Wolfe C, Morgan M. The SF-36 health survey questionnaire: Is it suitable for use with older adults? Age Ageing. 1995;24(2):120-25. [PMID:7793333] http://dx.doi.org/10.1093/ageing/24.2.120

25. Radloff LS. The CES-D scale. Appl Psychol Meas. 1977; 1(3):385-401. http://dx.doi.org/10.1177/014662167700100306
26. Weathers FW, Litz B, Huska J, Keane T. PCL-C for DSMIV. Boston (MA): National Center for PTSD-Behavioral Sciences Division; 1994.

27. Williams JE, Flora JA. Health behavior segmentation and campaign planning to reduce cardiovascular disease risk among Hispanics. Health Educ Q. 1995;22(1):36-48.

[PMID:7721600]

http://dx.doi.org/10.1177/109019819502200105

28. Olsen DG, Swigonski NL. Transition to adulthood: The important role of the pediatrician. Pediatrics. 2004;113(3 Pt 1):e159-62. [PMID:14993570] http://dx.doi.org/10.1542/peds.113.3.e159

29. Roebroeck ME, Jahnsen R, Carona C, Kent RM, Chamberlain MA. Adult outcomes and lifespan issues for people with childhood-onset physical disability. Dev Med Child Neurol. 2009;51(8):670-78. [PMID:19627341] http://dx.doi.org/10.1111/j.1469-8749.2009.03322.x

30. Gironda RJ, Clark ME, Massengale JP, Walker RL. Pain among veterans of Operations Enduring Freedom and Iraqi Freedom. Pain Med. 2006;7(4):339-43. [PMID:16898945] http://dx.doi.org/10.1111/j.1526-4637.2006.00146.x

31. Asmundson GJ, Coons MJ, Taylor S, Katz J. PTSD and the experience of pain: Research and clinical implications of shared vulnerability and mutual maintenance models. Can J Psychiatry. 2002;47(10):930-37. [PMID:12553128]

32. Bair MJ, Robinson RL, Katon W, Kroenke K. Depression and pain comorbidity: A literature review. Arch Intern Med. 2003;163(20):2433-45. [PMID:14609780] http://dx.doi.org/10.1001/archinte.163.20.2433

33. Prins MA, Verhaak PF, Hilbink-Smolders M, Spreeuwenberg P, Laurant MG, van der Meer K, van Marwijk HW, Penninx BW, Bensing JM. Outcomes for depression and anxiety in primary care and details of treatment: A naturalistic longitudinal study. BMC Psychiatry. 2011;11(1):180. [PMID:22099636] http://dx.doi.org/10.1186/1471-244X-11-180

34. Iversen AC, Fear NT, Ehlers A, Hacker Hughes J, Hull L, Earnshaw M, Greenberg N, Rona R, Wessely S, Hotopf M. Risk factors for post-traumatic stress disorder among UK Armed Forces personnel. Psychol Med. 2008;38(4):511-22. [PMID:18226287] http://dx.doi.org/10.1017/S0033291708002778

35. Phillips CJ, Leardmann CA, Gumbs GR, Smith B. Risk factors for posttraumatic stress disorder among deployed US male marines. BMC Psychiatry. 2010;10(1):52.

[PMID:20579379]

http://dx.doi.org/10.1186/1471-244X-10-52

36. Pietrzak RH, Johnson DC, Goldstein MB, Malley JC, Southwick SM. Psychological resilience and postdeployment social support protect against traumatic stress and depressive symptoms in soldiers returning from Operations Enduring Freedom and Iraqi Freedom. Depress Anxiety. 
2009;26(8):745-51. [PMID:19306303]

http://dx.doi.org/10.1002/da.20558

37. Rona RJ, Hooper R, Jones M, Iversen AC, Hull L, Murphy D, Hotopf M, Wessely S. The contribution of prior psychological symptoms and combat exposure to post Iraq deployment mental health in the UK military. J Trauma Stress. 2009;22(1):11-19. [PMID:19145644] http://dx.doi.org/10.1002/jts.20383

38. Norman SB, Trim RS, Goldsmith AA, Dimsdale JE, Hoyt DB, Norman GJ, Stein MB. Role of risk factors proximate to time of trauma in the course of PTSD and MDD symptoms following traumatic injury. J Trauma Stress. 2011; 24(4):390-98. [PMID:21834085]

http://dx.doi.org/10.1002/jts.20669
Submitted for publication June 8, 2013. Accepted in revised form October 9, 2013.

This article and any supplementary material should be cited as follows:

Larson GE, Norman SB. Prospective prediction of functional difficulties among recently separated Veterans. J Rehabil Res Dev. 2014;51(3):415-28.

http://dx.doi.org/10.1682/JRRD.2013.06.0135

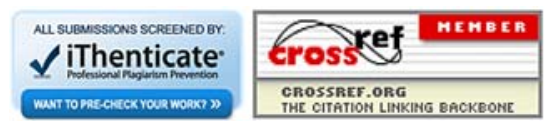


